\title{
Diablotexto
}

\section{El infinito vaivén. España y América Latina en Finisterre y Solo queda saltar, de María Rosa Lojo ${ }^{1}$}

The infinite swing. Spain and Latin America in Finisterre and Solo queda saltar, by María Rosa Lojo

\author{
LUCILA ROSARIO LASTERO \\ UNIVERSIDAD NACIONAL DE LA PLATA
}

Resumen: Finisterre (2005) y Solo queda saltar (2018), de María Rosa Lojo, narran historias de mujeres que enfrentan una doble pertenencia cultural, marcada por España y América Latina. En este trabajo, observaremos los mecanismos simbólicos que dan cuenta de la existencia de esa identidad fluctuante en cada una de las novelas mencionadas, e indagaremos en la posibilidad de una síntesis conciliatoria, a la que llamaremos el "vaivén identitario".

Palabras clave: pertenencia cultural, memoria, España, América Latina, identidad

Abstract: Finisterre (2005) and Solo queda saltar (2018), by María Rosa Lojo, narrate stories of women who face a double cultural belonging, marked by Spain and Latin America. In this work, we will observe the symbolic mechanisms that account for the existence of this fluctuating identity in each of the novels mentioned, and we will investigate the possibility of a conciliatory synthesis, which we will call "the identity swing".

Key words: cultural belonging, memory, Spain, Latin America, identity

\footnotetext{
${ }^{1}$ Este artículo se inscribe en el Proyecto de Investigación y Desarrollo "Memoria de migración, experiencia bélica y exilio. España y Argentina: representaciones literarias de y sobre mujeres en contextos de guerra, dictadura y destierro durante el siglo XX", código H897 de la Universidad Nacional de La Plata, dirigido por Mariela Paula Sánchez y codirigido por Adriana Virginia Bonatto.
} 


\section{Introducción: El dilema de estar entre dos mundos}

La narrativa de María Rosa Lojo se caracteriza por ahondar en las múltiples significaciones de los bordes. En sus textos, fronteras geográficas y culturales se entrecruzan y dialogan con las memorias personales y colectivas.

En esta oportunidad nos centraremos en dos de sus novelas: Finisterre (2005) y Solo queda saltar (2018), que guardan similitudes con respecto a los desplazamientos reales y simbólicos de los personajes femeninos, cuyas identidades se definen a partir de las relaciones entre España y América Latina en tanto puntos de partida y puntos de llegada sucesivamente. Las mujeres de estas novelas se encuentran ante el dilema de estar entre dos mundos, y no pertenecer ni al uno ni al otro, pero ser parte de los dos al mismo tiempo.

\section{Llegar al límite: La mujer entre culturas y las formas del cautiverio}

María Rosa Lojo es hija de españoles y nació en Buenos Aires. Su padre fue un republicano de Galicia que se exilió en Argentina luego de la Guerra Civil española. Actualmente, además de haber recibido varios premios y reconocimientos internacionales por su escritura, es docente en la carrera de Letras de la Universidad del Salvador (Buenos Aires), e investigadora del CONICET (Consejo Nacional de Investigaciones Científicas y Técnicas). Muchas de sus producciones se centran en las memorias familiares vinculadas a la inmigración española, y bucean en su propia historia personal.

"Pero creo que todos nosotros, [...] todos, tarde o temprano, alguna vez llegamos a Finisterre" (2005: 11), dice la carta con la que empieza la novela Finisterre, de María Rosa Lojo. Las palabras le pertenecen a Rosalind Kildare Neira, quien, desde Galicia, le escribe a Elizabeth Armstrong, una joven veinteañera que vive en Londres con su padre a fines del siglo XIX. Este será el principio de una serie de cartas enigmáticas cuyo sentido comenzará a develarse lentamente. Rosalind será la encargada de convencer a Elizabeth de la necesidad de ahondar en la memoria familiar y enfrentarse con su verdadera historia. Esta situación límite aparece simbolizada en la novela por "Finisterre", que, además de ser el nombre de un municipio español perteneciente a la 
provincia de La Coruña, en Galicia, significa "fin de la tierra" -finis terraesegún su etimología latina. Motivada por las cartas de Rosalind, Elizabeth deberá tomar coraje para enfrentarse a su propio Finisterre, bucear en el pasado familiar, explorar y reponer los vacíos de la memoria y contribuir, así, a su propia conformación identitaria.

El intercambio epistolar significará un camino en el que Rosalind irá deshilvanando su historia, al mismo tiempo que su receptora, Elizabeth, irá descubriendo la propia. La escritura será la herramienta simbólica que permitirá la conformación identitaria. Por eso Rosalind, cuando inicia su relato, habla de "reescribir" el pasado de Elizabeth: "Y creo saber bastante de Oliver Armstrong como para suponer que no sólo ha borrado mi nombre de tu vida, sino tu propia historia [...]. Yo puedo restituírtela, puedo reescribirla para ti” (2005: 15).

Rosalind Kildare Neira, de padre irlandés, vive en Galicia porque de allí es su familia materna. En el nombre de Rosalind está implícito un homenaje a Rosalía de Castro, escritora considerada símbolo de la cultura gallega. Esta autora es evocada desde el inicio de la novela por medio de unos versos que, a manera de epígrafe, aluden a la migración y a la idea del viaje: “¡Ánimo, compañeros! / Toda la Tierra es de los hombres. / Aquel que no vio nunca más que la propia / La ignorancia lo devora" (2005: 7). Estos versos de Rosalía de Castro, además, aparecen en lengua gallega junto a su correspondiente traducción al castellano.

Elizabeth Armstrong sabe que su madre, a quien no llegó a conocer, era del Río de la Plata y falleció cuando Elizabeth era muy chica, dejándole como única referencia un retrato que explicaría el porqué del cabello negro de la hija. Todo lo que Elizabeth desconoce sobre su madre es producto del silencio de su padre, Oliver Armstrong. Será Rosalind la encargada de reponer todo lo que este calló.

El señor Armstrong es un comerciante inglés convencido de que la cultura inglesa es superior a las del resto del mundo. No acepta su pasado en tierras rioplatenses y lo omite constantemente en la narración de su historia. Suele referirse con el mismo desprecio a los americanos y a los irlandeses, ya que estos últimos reclamaban su autonomía frente a Inglaterra por ese 
entonces. Durante una conversación con Elizabeth, dice de los irlandeses: "Como todos los bárbaros, son impermeables a la razón y a la ley, atados buena parte de ellos a una religión supersticiosa y a una lengua absurda" (2005: 17). Luego los compara con "los salvajes de la frontera" (2005: 17) que conoció en las pampas, y cuando su hija le pregunta si los americanos eran tan salvajes como los irlandeses, responde que "no hay mayor diferencia entre los unos y los otros" (2005: 17).

El relato que despliega Rosalind a través de las cartas tiene que ver con su experiencia como cautiva de los indígenas en la frontera argentina a mediados del siglo XIX. Llega a esas tierras junto a su marido médico, a quien le habían prometido un trabajo, pero el coche en el que viajan sufre una emboscada que provoca la muerte del hombre, y también la del hijo que Rosalind lleva en su vientre. Ella sobrevive gracias a la protección de Mira Más Lejos, un machi de la comunidad indígena de los ranqueles. Las machis son mujeres de la tribu que se encargan de la curación de dolencias. A pesar de que Mira Más Lejos es hombre, se identifica con el género femenino y se vuelve un confidente de Rosalind, a quien nombra su ayudante haciéndola pasar por machi. La conversión de Rosalind en machi implica la fusión cultural entre su origen gallego-irlandés y la sabiduría ancestral ranquel-mapuche. De esta manera, el encuentro entre Europa y América Latina es la clave para lograr la supervivencia de Rosalind.

La trama de Finisterre se desarrolla entonces a partir de dos enclaves temporo-espaciales: el presente de Elizabeth en Londres y el pasado de Rosalind en el Río de La Plata. Por medio del relato de Rosalind, Elizabeth va reconstruyendo su historia. De esta manera, textos, personajes y espacios conforman un diálogo que se desenvuelve en un contrapunto de espejos. Así como Elizabeth se descubre a sí misma a partir del intercambio con Rosalind, y viceversa, Europa y América Latina también se definen mutuamente de acuerdo a las características que las diferencian y las acercan.

Es muy significativo el hecho de que Rosalind rememore su pasado como cautiva por medio de cartas, ya que justamente los testimonios de las cautivas son una ausencia importante en la historiografía argentina. Solo los 
relatos de enunciadores varones -Ruy Díaz de Guzmán, Echeverría, Mansilla, Hernández- le dieron forma y voz al cautiverio femenino desde el siglo XVI hasta muy avanzado el XIX, cuando aparecen las primeras ficciones sobre cautivas por parte de autoras: Lucía Miranda, de Rosa Guerra y de Eduarda Mansilla, ambas novelas de 1860 y escritas sobre la base de la referencia de Ruy Díaz de Guzmán. Lojo, a través de la ficción, reivindica la voz silenciada de las cautivas. Por medio de Rosalind, la cautiva de Finisterre, asistimos a la intimidad de una primera persona que, a partir de la confianza que le proporciona el hecho de dirigirse a una receptora mujer y al carácter confidencial propio del género epistolar, nos permite ahondar en sus experiencias y emociones en tanto sujeto femenino vulnerado por el cautiverio. A través de un intercambio discursivo ficcional entre mujeres del siglo XIX, Lojo crea un espacio en el que la memoria, la identidad y la historia revelarán sus entrecruzamientos y conformarán al sujeto femenino en tanto entidad acallada por el discurso histórico oficial.

La experiencia de Rosalind como cautiva es relativamente favorable gracias a las acciones de Mira Más Lejos para protegerla. Sin embargo, ella sabe que sin esa protección sería como las demás, "una cautiva de ínfima clase: una mezcla abominable de prostituta y de sirvienta, una paria expuesta al desprecio de la aldea entera" (2005: 82). Rosalind también sabe del desprecio que sufren las cautivas que logran ser rescatadas, y a quienes se considera inferiores luego de la convivencia con el enemigo. Por eso, cuando se presenta la oportunidad del rescate, demora la decisión y hasta piensa en quedarse para siempre entre los ranqueles: “¿Me tratarían, allá afuera, como a una igual, o como una sirvienta poco fiable, por haber vivido entre los indios? ¿O me compadecerían, con el desdén mal cubierto de piedad que se le dedica a una mujer arruinada?" (2005: 142).

Luego de varios años de convivencia con los ranqueles, Rosalind reconoce que ese relativo bienestar del que disfruta, pese a su cautiverio, tiene que ver con su proceso favorable de adaptación. A diferencia de otros personajes cautivos, ella acepta ser una mujer entre dos culturas, y, desde su lugar de machi, lucha por la integración de los saberes, las costumbres, las 
lenguas. Rescata la valija con instrumentos y medicamentos de su esposo muerto y los pone al servicio de la comunidad indígena por medio de Mira Más Lejos. Por ejemplo, una de las escenas narra el asombro del machi cuando descubre el estetoscopio, que luego incorporaría a sus prácticas.

De esta manera, lo que la cultura occidental llama "brujería", práctica que persiguió y condenó durante muchos años, es lo que salva a Rosalind en las nuevas tierras. La investigadora italiana Silvia Federici aborda la relación entre mujer y hechicería en su libro Calibán y la bruja ([2004] 2015), donde afirma que "Históricamente, la bruja era la partera, la médica, la adivina o la hechicera del pueblo, cuya área privilegiada de incumbencia [...] era la intriga amorosa" (2015: 276). Según Federici, la ciencia moderna reemplazó a la bruja-curandera por el doctor y "Con la persecución de la curandera de pueblo, se expropió a las mujeres de un patrimonio de saber empírico, en relación con las hierbas y con los remedios curativos, que habían acumulado y transmitido [...]" (2015: 278). Siguiendo a la investigadora italiana, Rosalind se convierte en una representante de ese saber ancestral que el poder masculino se propone eliminar, como parte del ocultamiento de las capacidades femeninas.

Por otra parte, Rosalind también realiza intentos de integrar al nuevo mundo a los otros cautivos, entre quienes se destacan doña Ana, una actriz de teatro española, y Oliver Armstrong, un comerciante inglés que es nada menos que el padre de Elizabeth, en su juventud. Pero las acciones de Rosalind son infructuosas, ya que tanto doña Ana como Armstrong rechazan la idea de fusionar su cultura con aquella otra a la que consideran bárbara e indigna de su persona. Por medio de doña Ana, aparecerá otra idea de cautiverio, ya que esta actriz sumamente vanidosa, antes del rapto, le confiesa a Rosalind una pena de amor que obstaculiza su libertad: "Sufro el peor de los cautiverios: vivo presa de un amor desgraciado" (2005: 37).

En cierto momento Elizabeth reflexiona sobre los sucesos que le narra Rosalind en sus cartas y piensa: "Siempre se es cautivo, al parecer, en el mundo ajeno" (2005: 67). Una de las conclusiones a la que arriban las protagonistas principales de esta novela, tanto Rosalind como Elizabeth, es que el cautiverio es más simbólico que empírico. No es necesario estar 
atrapado para ser un cautivo. Lo es quien no está conforme con el nuevo territorio en el que vive y no puede conciliar su cultura de origen con la nueva. Doña Ana y Oliver Armstrong fueron realmente cautivos de los ranqueles, porque durante la convivencia con ellos no lograron asimilar y comprender los códigos de la comunidad indígena, en el afán de enarbolar continuamente la superioridad de la cultura propia. Rosalind, en cambio, integra sus saberes de origen con los ancestrales de la pampa argentina, produciendo una fusión cultural que acerca los mundos en lugar de alejarlos. La "libertad" de Rosalind se debe a la aceptación de una identidad múltiple.

Mientras tanto, en el contexto temporo-espacial de Elizabeth, se revelan otras formas de libertad y de cautiverio. La tía Audrey Armstrong es una mujer libre, porque la viudez y el hecho de no haber tenido hijos la eximen de las tareas domésticas y le permiten viajar y reunirse con amigos con frecuencia. Otro personaje de la historia, Doña Manuela, manifiesta sus deseos de libertad y se queja de la vida hogareña cuando dice "cautiva estoy yo en esta salita, entre cuatro sillones y un piano. Si no fuera por mi marido y mis hijos..." (2005: 67). Oliver Armstrong, por su parte, más allá de la buena relación con su hija, sentencia "Las niñas pertenecen a sus padres, por supuesto" (2005: 31). La investigadora Marcela Lagarde, en su libro Los cautiverios de las mujeres. Madresposas, monjas, putas, presas y locas (2005) se refiere a estas otras formas de cautiverio que se enlazan directamente con lo doméstico y que perviven en la historia solo cambiando sus estrategias, pero manteniendo el objetivo de controlar e impedir el desenvolvimiento social de las mujeres.

Tanto el relato de la vida de Rosalind entre los ranqueles como la cotidianeidad de Elizabeth en Londres avanzan a la par de continuos contrastes y similitudes entre Europa y América Latina, y entre España y el Río de la Plata. De la comparación entre espacios también deriva la que puede hacerse entre Madrid y Galicia dentro del territorio español. Durante una conversación con doña Ana, mientras esta última exalta el buen nivel de los teatros españoles, Rosalind piensa en el vínculo entre regiones centrales y marginales: 
Tampoco nosotros podíamos impedir las comparaciones; aunque no entre Madrid y el Río de la Plata, sino entre Madrid y nuestra famélica Galicia, que cada año enviaba más impuestos al gobierno central, y también más indigentes y más analfabetos para servir en los campos o en las casas ricas de las ciudades castellanas. (2005: 27)

La representación de Galicia como marginal y desolada, finalmente permite su asimilación directa con la pampa argentina. Cuando Frederick Barrymore, amigo de Elizabeth, la escucha hablar de las cartas que recibe desde Finisterre, dice: "No he conocido paraje más desolado en el planeta. Salvo algunos lugares de la pampa argentina" (2005: 59). Por su parte, Rosalind, durante su proceso de adaptación a las nuevas tierras, llega a percibir, en los discursos de Armstrong y de doña Ana, la reproducción de las dinámicas de los centros y los márgenes, que conllevan el menosprecio a los habitantes de estos últimos. Ante la expresión "hato de orangutanes" (2005: 62) de Ana, Rosalind declara: "Empecé a sentirme absurdamente molesta, como si me hubieran mentado a alguien de la familia. Acaso porque, en España, la soberbia de Castilla nos miraba a los gallegos como a otros indios" (2005: 62).

Las cartas de Rosalind dejan de llegar luego de revelarle a Elizabeth toda la verdad sobre su madre indígena. El fin de la correspondencia será el inicio de la reconciliación definitiva de Elizabeth con su pasado. Decide viajar al Río de la Plata y será otra mujer, su tía Audrey, la que aceptará acompañarla en su travesía por Argentina. Vemos que son mujeres las principales confidentes y compañeras de Elizabeth; Rosalind y Audrey, cada una a su modo, la ayudará a descubrirse y la acompañará en ese autoconocimiento. De esta manera, queda conformado un universo femenino que encierra los códigos de un lenguaje que los varones no pueden comprender. En esta alianza entre mujeres podemos encontrar las características propias de un concepto muy usado en la actualidad: sororidad ${ }^{2}$, aunque en la fecha de

\footnotetext{
${ }^{2}$ Este término nace en el seno de los movimientos feministas, de la mano de Marcela Lagarde, referente académica. La sororidad se basa en derribar la falsa creencia, promulgada por el discurso machista, de que las mujeres son enemigas entre sí. Busca promover, además, el diálogo y la amistad entre mujeres para hacer frente a las estrategias de dominación patriarcal. Según la antropóloga mexicana Marcela Lagarde, "La sororidad es en esencia trastocadora: implica la amistad entre quienes han sido creadas por el mundo patriarcal como enemigas" (1998: 18). Lagarde afirma que la sororidad supone recuperar los afectos y cuidados que las mujeres imparten hacia los demás, y proferírselos a sí mismas: "La sororidad es la posibilidad
} 
publicación de esta novela aún no se había popularizado. La investigadora Marcela Lagarde define a la sororidad como esa fraternidad entre mujeres que pretende actuar como protección ante el avasallamiento patriarcal. En esta novela, la conjunción de identidades femeninas y el diálogo entre ellas servirá para contrarrestar el autoritarismo del varón, representado por el padre de Elizabeth.

A Elizabeth, el símbolo del mestizaje y de un espacio negado y silenciado por un padre europeo, le corresponde volver a la Argentina para concretar la reconciliación, la redención con la tierra. Este encuentro con su pasado y con su lugar de origen le permitirá a la protagonista reconstruir su identidad y, a su vez, redimir a su padre. Así, la novela Finisterre es la narración del periplo de una mujer que decide recorrer el camino que la conducirá hasta ese límite que la enfrentará con la multiculturalidad que la constituye. Elizabeth representaría al ciudadano argentino que busca encontrarse por fin con ese lado "bárbaro" que le pertenece y que lo conforma, pero que los mecanismos del poder pretendieron ocultarle.

\section{Pegar el salto: La aceptación de una identidad múltiple}

Solo queda saltar fue publicada por primera vez en 2018 y recibió, ese mismo año, un premio de la Asociación de Literatura Infantil y Juvenil de la Argentina (ALIJA). Cuenta la vida de dos hermanas que llegan a Buenos Aires siendo niñas, tras haberse quedado huérfanas en su Galicia natal. En las nuevas tierras deberán aprender a convivir con el tío Juan, a quien no conocen de antes, y con una lengua y una cultura distintas. Por otra parte, tendrán que resignificar los recuerdos y las vivencias que traen desde su país de origen.

de usar para nosotras mismas, en la alianza, los conocimientos y las prácticas amorosas, los cuidados afectivos e íntimos que, en la división genérica del mundo como madres, volcamos hacia los hombres y hacia los otros" (1998: 19). 
La estructura de la novela se organiza de acuerdo a dos partes: el Cuaderno de Celia (1948), y el Cuaderno de Isolina (2018). El de Celia está conformado por memorias de la infancia y la juventud durante los primeros años en tierras argentinas, en tanto que el de Isolina, setenta años después, es una narración desde la vejez durante una visita a Fisterra, el lugar de origen. Por medio de los cuadernos, la escritura se presenta como imprescindible para la materialización de la memoria. En el segundo capítulo correspondiente al Cuaderno de Celia, ella recuerda las palabras de su padre al respecto:

Escríbelo. Regístralo. Apúntalo. Nadie sabe que dentro de un bloque de mármol hay escondido un cuerpo, una cara, unos ojos que miran los tuyos, hasta que los descubre un escultor. Así es con lo que sientes, con lo que piensas, cuando lo ves escrito. (Lojo, [2018] 2019: 11)

Así, la necesidad de plasmar por escrito las vivencias tiene la misma potencia y significación que en Finisterre, y escritura y memoria forman parte de un recorrido que permite a las protagonistas reencontrarse consigo mismas, y a su vez aportar a la revalorización de otros trayectos individuales y culturales.

Como en Finisterre, se observa la presencia de la tradición literaria gallega, por medio de la mención a Rosalía de Castro. El tío Juan, el familiar que alberga en Argentina a las hermanas huérfanas, conserva libros escritos en gallego, como una forma de sentirse más cerca de su tierra. Entre esos libros, hay uno de Rosalía de Castro.

Celia e Isolina son parte de una de las últimas oleadas inmigratorias españolas. En su cuaderno de memorias, Celia adjudica el retraso del viaje a las esperanzas puestas en una posible caída de Francisco Franco:

\footnotetext{
Hace un tiempo que no llegan nuevos grupos de españoles. Somos parte de la última ola: las esquirlas, la resaca que trajeron el hambre y la orfandad de nuestra guerra. Algunos estuvieron esperando a que los ganadores de la otra guerra, la más grande, la que mató a millones de personas a lo largo de Europa y fuera de ella, se apiadaran de España. Que la curasen del Generalísimo Franco con su poder y su conocimiento, como se cura una enfermedad terca y terrible. (2019: 24)
}

Las características de los inmigrantes gallegos se definen entonces no solo por su extranjería y por hablar una lengua distinta, sino también por las secuelas emocionales y corporales provocadas por la guerra y la opresión de un gobierno autoritario. 
Durante una visita a Los Toldos, Celia y su amigo Gustavo conocen a doña María, una machi que logra ver, en las manos de Gustavo, la huella de un dolor pasado. Así, en Solo queda saltar, como en Finisterre, la cultura ancestral se hace presente por medio de la figura de la machi. Doña María también ve al lenguaje como esencial para el autoconocimiento, pero, lejos de exaltar la escritura, destaca la oralidad. En relación con el silencio de una de las jóvenes, sentencia: "Que ella diga, porque la palabra hace más fuertes a las personas. Y las cura. Hay que sacarla de adentro para limpiar el alma, como se limpian las heridas" (2019: 114). Por su parte, al igual que Rosalind en Finisterre, doña María es una sobreviviente de las guerras de militares argentinos contra indígenas, ya que su madre y su hermano padecieron las matanzas efectuadas durante la llamada Conquista del Desierto.

Isolina, en su cuaderno de memorias, compara a la machi indígena con la meiga gallega:

Así les decíamos en Galicia a las que la gente de "La Tribu", en Los Toldos, llamaba machis, en lengua mapuche. Se vestían de manera parecida y hacían más o menos lo mismo: curaban con infusiones, cataplasmas, emplastos y una abundante y persuasiva reiteración de rezos; sus saberes venían de tiempos más antiguos que la Iglesia y sus latines. Meigas y machis eran sanadoras populares en tierras pobres. (2019:112)

A lo largo de la narración, son frecuentes las comparaciones entre Galicia y Argentina, y se hace hincapié en los rasgos humanos y en las prácticas culturales que definen quiénes son los marginales en cada grupo social. Por eso, cuando se pone en paralelo la situación de las curanderas gallegas y las curanderas argentinas, se observa una similitud con respecto a la subestimación que sufren por parte de sus propias culturas, luego de haber sido demonizadas por los centros de poder. La condición de extranjería y la pobreza también son puestas en paralelo, como dos maneras de no pertenecer al sistema: "Ser extranjero y ser argentino y pobre suelen pagar el mismo tributo" (2019: 63).

Esta asimilación entre extranjería y pobreza se concreta en la amistad entre Isolina e Ignacia, una jovencita pobre de ascendencia indígena. Juntas se escapan hacia Los Toldos y reciben la protección de la machi doña María. Isolina e Ignacia descubren que, en el fondo, son iguales, porque ser 
inmigrante y ser indígena las coloca en el mismo nivel de marginalidad, y la exploración de los orígenes, en cada caso, estrecha aún más los lazos entre las culturas.

El cuaderno de Celia está atravesado por un sueño recurrente. La niña no logra descifrar si esas imágenes, que la muestran como víctima de una persecución en medio de la noche, son parte del recuerdo de algo que de verdad pasó en su vida. Finalmente, con la ayuda de su tío Juan, logra entender que se trata de un suceso real, del cual fue protagonista en su tierra de origen. Este hecho le genera culpa, la ata de manera negativa a su pasado, y funciona como obstáculo para la adaptación a la nueva vida. La colaboración del tío en la reconstrucción de los recuerdos de Celia tiene que ver con lo que postula Maurice Halbwachs en La memoria colectiva ([1968] 2004) sobre la necesidad de recurrir a otros testimonios para completar la memoria propia:

Pero nuestros recuerdos siguen siendo colectivos, y son los demás quienes nos los recuerdan, a pesar de que se trata de hechos en los que hemos estado implicados nosotros solos, y objetos que hemos visto nosotros solos. Eso se debe a que en realidad nunca estamos solos. (2004: 26)

Según Halbwachs, ninguna vivencia ni recuerdo es completamente individual, ya que siempre interactúan con las vivencias y recuerdos de otras personas. De esta manera, en Celia e Isolina vemos cómo el vínculo cercano con el tío Juan, un familiar también inmigrante, les permite resignificar el pasado en Galicia. Las niñas y el tío Juan comparten una memoria fragmentada entre los recuerdos de la vieja patria y los de la nueva. La integración entre unos y otros es lo que posibilitará la aceptación de una identidad múltiple.

De esta manera, en Celia e Isolina vemos al "extranjero" que caracteriza el filósofo y sociólogo alemán Georg Simmel (2012). El extranjero es, para Simmel, no aquel que llega y se va, sino el que está en interacción constante con su lugar de origen: "el emigrante potencial ${ }^{3}$ que, aunque se haya detenido, aún no ha superado la ausencia de vínculo propia del ir y venir" (2012: 21). Las hermanas perciben que sus vidas están ancladas tanto en España como en

\footnotetext{
${ }^{3}$ En cursiva en el original. 
Argentina, por eso, cuando Celia se entera de la venta de la antigua casa de su niñez en Galicia, se entristece por la pérdida de lo que aún considera suyo: "No tengo ya hogar a donde volver. No hay una habitación, un árbol, una piedra en toda Galicia a los que pueda llamar míos. Quemamos las naves. Quedamos del lado de afuera" (2019: 70-71).

El cuaderno de Isolina, escrito desde la vejez y desde el presente, cierra la novela. Por ella nos enteramos de la vida de las hermanas durante esos setenta años que transcurrieron entre un cuaderno y otro: los estudios, los amores, las revelaciones familiares, las noticias sobre personajes de la cultura y la política argentina, como Victoria Ocampo y Eva Perón. La mención de sucesos y de personajes históricos en la novela evidencia que la memoria histórica -aquella construida por el discurso histórico oficial- está siempre en relación con la memoria colectiva y con la memoria individual, como afirma Halbwachs. Isolina también cuenta que Celia se casa y tiene un hijo, que más tarde es asesinado y pasa a formar parte de la nómina de desaparecidos durante la dictadura militar argentina de 1976. Hojas sueltas escritas por Celia y fechadas en 1980 se refieren a la desaparición del hijo: "Desaparecido. Sin entidad. Sin nombre, sin justicia, sin derechos. Girando en la nada” (2019: 141).

Jacques Hassoun en su libro Los contrabandistas de la memoria (1996) se refiere a la transmisión necesaria de una cultura, una creencia, una historia, que se da de padres a hijos. Según Hassoun, la transmisión genera un encadenamiento en donde "toda transmisión es re-transmisión, es decir que ya se encuentra sometida a las modificaciones inherentes a toda re-modelación del pensamiento" (1996: 169-170). Con la pérdida del hijo, se produciría, por un lado, la ruptura de ese encadenamiento, ya que no habrá más descendencia a quien legar la memoria de la inmigración iniciada con Celia. Por otra parte, esta desaparición le muestra a Celia la circularidad de su propia vida: "También nosotros, Gustavo y yo, nos hemos vuelto fantasmas de todos los mundos, como Manuel. Y como el fantoche del bigote, nos movemos en un mapa de carriles, ordenanzas y reglamentos" (2019: 141). La experiencia de Celia como extranjera la llevó a sentirse un fantasma durante sus primeros años en la 
Argentina. Luego de muchos años y de la adaptación al nuevo suelo, vuelve a sentirse nadie frente a la ausencia del hijo.

Es significativo que la voz de Isolina, al final de la novela y con el fin de recuperar lo vivido por las hermanas durante los años anteriores, se intercale con un paseo por Galicia junto a su amiga Ignacia. Isolina cierra el círculo de su trayectoria vital regresando al lugar que la vio partir, y recordando sus experiencias en Argentina desde ese lugar, así como durante tanto tiempo rememoró Galicia desde Argentina. La memoria se traslada desde un lugar a otro en un contrapunto infinito, como lo hacen sus habitantes: "Desde que yo recuerdo, o desde que me contaron, durante siglos, siempre hubo alguien de la familia que se fue a las Américas. Y siempre alguien volvió.” (2019: 129), le comenta Isolina a Ignacia.

Solo queda saltar es la narración de un periplo migratorio que se define como circular, ya que la identidad propia se conforma a partir de un ida y vuelta entre espacios y sucesos que se repiten. Celia dice: "Vivo mi vida en círculos crecientes, que se dibujan sobre las cosas" (2019: 143). Por otra parte, la novela da cuenta de una oscilación que definiría la condición migrante, caracterizada por una memoria que hace pie en un lado e inmediatamente en otro, sin detenerse jamás. Isolina reflexiona, durante su vuelo de Galicia a la Argentina, atravesando el océano: “¿Será la última vez? ¿Por fin aquí se detendrá el vaivén? / [...] / Yo soy el vaivén. / Cuando me voy, nada dejo, porque todo viaja conmigo." (2019: 149).

La novela se titula Solo queda saltar porque, ante ese fin de la tierra, no queda otra que aventurarse y avanzar, pese al abismo, lo que equivaldría a asumir que la nueva tierra es la extranjera, pero que una parte de la historia personal seguirá siempre enclavada en otro lugar al mismo tiempo, y es necesario aprender a convivir con la identidad múltiple y con las oscilaciones de la memoria. 


\section{Permanecer / oscilar}

María Rosa Lojo hace de Finisterre -Fisterra, en gallego-, una metáfora. Este símbolo forma parte de lo que tienen en común las novelas Finisterre y Solo queda saltar, ya que ambas exploran las significaciones de esta nominación. Durante la Guerra de las Galias, este lugar fue considerado por los romanos el fin del mundo, ya que veían imposible que hubiera algo más allá. En las novelas abordadas, ese fin de la tierra significa, metafóricamente, un momento decisivo en la vida de cada persona, por lo tanto, todos tendremos algún día nuestro Finisterre. En Solo queda saltar, la señora Brey le dice a Celia:

No hay quien no lleve dentro su Fisterra. Aunque no haya salido nunca de su ciudad o de su aldea. Pobres o ricos, protegidos o a la intemperie, llega el momento en que se nos exige más de lo que creemos poder dar. En que chocamos contra lo desconocido y afrontamos el terror de no ser más. No ser ya quienes éramos y no poder ser otros. No encontrar las nuevas claves para seguir viviendo. $Y$ es así a cualquier edad, desde el principio hasta el fin. También debemos aprender cómo envejecer y cómo morir" (2019: 38)

También en Finisterre aparece esta idea, ya a partir de la primera carta que le manda Rosalind a Elizabeth. En las dos novelas se destaca la importancia de hacer frente a esa instancia límite y "pegar el salto" en lugar de retroceder; esto es, atreverse a ir más allá. Como dice Celia, "En el borde del mundo, en el borde de la vida, solo queda saltar" (2019: 25).

En su libro La "barbarie" en la narrativa argentina siglo XIX, María Rosa Lojo explora los alcances del concepto "civilización", la construcción de su opuesto ("barbarie") en la Argentina, y analiza algunas obras literarias claves para comprender esta dupla definitoria de la conformación nacional. En este libro, Lojo cita a Héctor Murena para referirse a su ensayo El pecado original de América (1954), en el que se habla de una suerte de segunda expulsión del Paraíso sufrida por los conquistadores españoles en tierras americanas. Se trata de un castigo por no haber sabido visibilizar y entender la alteridad. Lojo afirma: 
América se muestra así, en la lectura de Murena, como el Anti-Edén, la contrainocencia, el territorio del pecado, el aborrecimiento, la sospecha. Si el Edén es el comienzo [...], el Anti-Edén americano no es el Principio sino el Finisterrae ${ }^{4}$. (1994: 32)

En Finisterre y en Solo queda saltar, Lojo propone desestructurar las dicotomías que funcionan como oposiciones fijas. De esta manera, no existiría un lugar representativo de la "civilización" y otro lugar representativo de la "barbarie", porque se trataría simplemente de culturas distintas y, a su vez, capaces de contener a grupos humanos más o menos similares dentro de sus propios límites. Por otra parte, Lojo parte de la lectura sobre América Latina realizada por Murena, para borrar las distancias entre Edén y Anti-Edén. Así, la relación entre españoles y latinoamericanos es de conciliación, más allá de cualquier jerarquía, idealización o estigma: América no es Edén ni Anti-Edén; es ambos y ninguno al mismo tiempo.

Otra oposición lógica que se rompe es la que existe entre lo bueno y lo malo. Por ejemplo, en Finisterre, a través de sus prácticas como machi, Rosalind salva su vida y cumple su sueño de ser médica, profesión que en su tierra de origen es inconcebible para una mujer. De esta manera, rompe con la distancia entre lo bueno y lo malo a partir de la fusión cultural: "por eso la hija del médico, la señorita de aldea, pudo ser también una hechicera que obraba el bien y obraba el mal, porque lo bueno para uno es malo para otros" (2005: 130). El bien y el mal son relativos porque no dependen nada más que de construcciones culturales que varían de un lugar a otro.

Stuart Hall afirma que la identidad es, fundamentalmente, un proceso que nunca es definitivo, y que se construye por medio de las diferencias. El establecimiento de diferencias, y al mismo tiempo de similitudes entre espacios (Europa / España / Galicia y América Latina / Argentina) tiene que ver con esta búsqueda constante, tanto en los personajes de Finisterre como en Solo queda saltar.

Para Hall, las prácticas discursivas son esenciales en el proceso de conformación de las identidades: "las identidades son puntos de adhesión temporaria a las posiciones subjetivas que nos construyen las prácticas

\footnotetext{
${ }^{4}$ En cursiva en el original. 
discursivas" (2003: 20). Por eso, en las novelas abordadas, la escritura toma la forma de cartas o de cuadernos de memoria que tienen como objetivo ahondar en la memoria por medio del discurso.

En relación a los vínculos entre memoria e identidad, Vincent de Gaulejac sostiene:

\begin{abstract}
Memoria e identidad son imposibles de disociar. Se refuerzan mutuamente, desde el momento en que surgen hasta su ineluctable disolución. No hay búsqueda de identidad sin memoria y, a la inversa, la búsqueda de la memoria siempre va acompañada por un sentimiento de identidad, al menos individual. (2002: 33)

Celia da cuenta de la oscilación mientras piensa en los inmigrantes como su tío Juan, que ya lleva muchos años en la Argentina. Ella cree que existe un tiempo empírico y otro simbólico, que sería el tiempo de los que siempre están volviendo a su tierra por medio de los recuerdos:

Yo creo que es otra cosa. Que viven en dos tiempos. Uno es el de América, el lugar a donde llegaron arrastrados por el viento y se posaron, ligeros como los vilanos de las flores de cardo. Se enredaron en los pastos, desmadejándose poco a poco, perdiendo pelos, fibras, cuerpo, borrándose en la llanura. El otro es un tiempo que no transcurre, inmóvil y circular, al que siempre se vuelve, hecho de lugares indestructibles, de caras que nunca se ajan. (Lojo, 2019: 19- 20)
\end{abstract}

Así, mientras Finisterre termina con el viaje en barco de Elizabeth hacia el Río de la Plata y el regreso de Rosalind a Galicia, en Solo queda saltar los capítulos finales están marcados por la visita de Isolina a Fisterra. Ir y venir entre territorios, para reconocerse en ellos, es parte de ese vaivén infinito que es necesario asumir.

María Rosa Lojo forma parte de una generación de hijos de inmigrantes que experimentan el "exilio heredado". Esta autora configura un espacio ficcional desde donde problematiza los desplazamientos de la memoria individual, la memoria colectiva y las historias nacionales, con el fin de cimentar la indagación sobre su propia configuración identitaria.

\title{
A manera de conclusión: el vaivén identitario
}

¿Qué hacer con nuestras respectivas historias familiares? ¿Cómo conciliar orígenes culturales distantes y disímiles? Las novelas Finisterre y Solo queda saltar, de María Rosa Lojo, intentan dar una respuesta a estos 
interrogantes. Ambas son narraciones que desmienten la posibilidad de una identidad unívoca, ya que sus protagonistas oscilan entre una pertenencia cultural -la de origen-y otra -aquella en la que se insertaron posteriormente.

En estos relatos se evidencian no ya las distancias sino los vínculos entre la cultura europea-española, y la latinoamericana. Para ello, Lojo reescribe los sentidos de la conquista y colonización española, que da origen a las duplas conquistadores/conquistados y civilizados/bárbaros, y propone una deconstrucción de las antinomias a partir de la observación de las similitudes. Los puntos en común entre España y América Latina devienen de ahondar en sus respectivas historias y, sobre todo, de valorar sus saberes ancestrales. Así, la cuestión de "civilización" y "barbarie", en las novelas estudiadas, no se limita solamente al espacio pampeano, sino que se extiende hacia tierras españolas, donde también existen conflictos étnico-culturales plenamente vigentes. En el migrante se concretaría la síntesis de las culturas, ya que, siguiendo a Georg Simmel, el extranjero se encuentra en constante interacción con su lugar de origen, por medio de un ir y venir de la memoria. Así, los términos "civilización" y "barbarie" son puestos en cuestionamiento y la doble o múltiple identidad deja de ser un problema para convertirse en parte constituyente de los sujetos.

Esa identidad múltiple y en permanente construcción, propia del extranjero, no se resuelve en una sola dirección, sino que fluctúa siempre. El vaivén es lo que sigue al Finisterre, porque la presencia del límite no significa retroceder sino saltar, aventurarse a la oscilación e incorporarla como parte esencial de la vida.

\section{Biblografía}

De Gaulejac, Vincent (2002). "Memoria e historicidad". Traducción de Haydeé Silva Ochoa, Revista Mexicana de Sociología, vol. 64, n. 2 (Apr.-Jun.), pp. 31-46.

Federicl, Silvia [2004] (2015). Calibán y la bruja. Mujeres, cuerpo y acumulación originaria. Traducción de Verónica Hendel y Leopoldo Sebastián Touza. Buenos Aires: Función Oblicua. 
HALL, Stuart (2003). “1. Introducción: ¿quién necesita 'identidad'?”. En Stuart Hall y Paul du Gay, Cuestiones de identidad cultural. Buenos Aires: Amorrortu.

HaLBWACHS, Maurice [1968] (2004). La memoria colectiva. Traducción de Inés Sancho- Arroyo. Zaragoza: Prensas Universitarias de Zaragoza.

HASSOUN, Jacques (1996). Los contrabandistas de la memoria. Traducción de Silvia Fendrick. Buenos Aires: Ediciones de La Flor.

LAGARDE, Marcela (2005). Los cautiverios de las mujeres. Madresposas, monjas, putas, presas y locas. México: Universidad Nacional Autónoma de México.

LAGARDE, Marcela (1998). "Enemistad y sororidad: Hacia una nueva cultura feminista", en <http://e-mujeres.net/wpcontent/uploads/2016/08/Enemistad-y-sororidad.pdf> [Fecha de consulta: 2 de agosto de 2020].

LoJo, María Rosa [2018] (2019). Solo queda saltar. Buenos Aires: Santillana.

Lojo, María Rosa (2013). "El exilio heredado: raíz de la escritura y herida de la memoria",

$<$ https://dialnet.unirioja.es/servlet/articulo?codigo=4536765> [Fecha de consulta: 3 de agosto de 2020].

LoJo, María Rosa (2005). Finisterre. Buenos Aires: Sudamericana.

Lojo, María Rosa (1994). La "barbarie" en la narrativa argentina siglo XIX. Buenos Aires: Corregidor.

SiMmEL, Georg (2012). El extranjero. Sociología del extraño. Madrid: Sequitur.

Fecha de recepción: 7 de agosto de 2020 .

Fecha de aceptación: 12 de noviembre de 2020. 